\title{
Experience in the diagnosis of headaches that start in elderly people
}

\author{
Julio Pascual, José Berciano
}

\begin{abstract}
The diagnoses of the 193 patients aged 65 and over who attended the service of neurology in the past 15 years with de novo headache as their initial and main symptom were specifically analysed. Headaches beginning in elderly people represented only $5.4 \%$ of headaches in all ages, whereas $12 \cdot 1 \%$ of the population in this health area was 65 or over. Head pain appeared more often in women (63\%), although post-traumatic, cluster, and benign cough headaches were almost restricted to men. Tension type headache (83 patients, $43 \%$ of the aged patients) and idiopathic trigeminal neuralgia (36, $19 \%)$ were the most frequent diagnoses. Fifteen per cent of the elderly patients $v$ $1.6 \%$ of patients under 65 presented headache secondary to serious conditions, such as stroke, temporal arteritis, or intracranial neoplasm. Only one patient over 65 met migraine criteria. It is concluded that whereas the incidence of patients with headache attending a general hospital decreases with age, the risk of headaches due to serious conditions increases 10-fold after 65 .
\end{abstract}

(F Neurol Neurosurg Psychiatry 1994;57:1255-1257)

Although most epidemiological studies on headache, even the most recent, ${ }^{1}$ have focused on younger people, headache is not an uncommon complaint of elderly people. In one large series of people over 65 years of age, $17 \%$ reported frequent headaches. ${ }^{2}$ Other investigations estimate the frequency of headaches in the elderly population anywhere from $5 \%{ }^{3}$ to $50 \%,{ }^{4}$ with most reports indicating that women have headache more often than men. ${ }^{3-8}$ These studies have shown that there are predictive variables strongly associated with the appearance of headache in elderly people-namely, pain in the neck and back, depressive symptoms, and the patient's self assessed state of health. Other factors related to an increase in headache include impaired vision, ischaemic heart disease, joint pain, and sleep disturbances. ${ }^{2-4}$ In elderly people, the prevalence of most symptoms tends to increase; however, this phenomenon has not been shown to occur with headache. ${ }^{9}$
There is little information available on the frequency distribution of headaches beginning for the first time in old age. In this work we analysed the diagnosis of headaches that appeared de novo in a general hospital population aged 65 and older.

\section{Patients and methods}

All the medical charts of patients attending our service with headache as their main complaint were reviewed. We specifically concentrated on the clinical records of patients aged 65 or over. Since 1974, the service of neurology of the University Hospital "Marqués de Valdecilla" has received neurological patients directly from general practitioners, who have to send us both ambulatory and emergency patients in the area with headache. There are no other hospitals, either public or private, admitting neurological problems in our region. According to official Spanish census data, the number of inhabitants in this health area ranged between 340000 and 360000 (348 571 in the middle of this work), whereas those aged 65 and over represented $12 \cdot 1 \%$ of the total population.

Patients were included in this study only if: (1) headache had been both the initial and main complaint, and (2) the clinical diagnosis had been performed, after an appropriate follow up, by one of the staff neurologists. Therefore, we excluded patients with headache, but in whom headache was not the presenting or main symptom for consultation.

Final headache diagnosis was performed according to current operational criteria. ${ }^{10}$ Only those patients with headache after lumbar puncture were not included in this series.

Patients were entered in this study provided that they had attended our service from 1978, when CT was first available in our institution, to the end of 1992.

\section{Results}

The table summarises the results of the present study. Of the 3578 patients who had attended our service with headache as their main symptom, in $193(5.4 \%)$ the head pain had begun for the first time in their lives when aged 65 years or older.

In these elderly patients, headaches appeared more often in women (122 cases, 
Diagnosis and sex distribution of headaches appearing in elderly patients $(n=193)$ compared with all headaches $(n=3578)$

\begin{tabular}{|c|c|c|c|c|c|c|}
\hline \multirow[b]{2}{*}{ Headache diagnosis } & \multirow{2}{*}{$\begin{array}{l}\text { No } \\
<65 y\end{array}$} & \multirow{2}{*}{$\begin{array}{l}\text { No } \\
\geqslant 65 y\end{array}$} & \multirow[b]{2}{*}{$p$ Value ${ }^{*}$} & \multirow[b]{2}{*}{$\%>65 y$} & \multirow{2}{*}{$\frac{\text { Ment }}{\text { No (\%) }}$} & \multirow{2}{*}{$\frac{\text { Woment }}{\text { No (\%) }}$} \\
\hline & & & & & & \\
\hline Tension type & 1030 & 83 & $<0.001$ & $43 \cdot 0$ & $20(24)$ & $63(76)$ \\
\hline Idiopathic trigeminal neuralgia & 68 & 36 & $<0.001$ & $18 \cdot 7$ & $9(25)$ & $27(75)$ \\
\hline Subarachnoid haemorrhage & 32 & 15 & $<0.001$ & $7 \cdot 8$ & $5(33)$ & $10(67)$ \\
\hline Temporal arteritis & 1 & 12 & $<0.001$ & $6 \cdot 2$ & $5(42)$ & $7(58)$ \\
\hline Intracranial neoplasm & 23 & 8 & $<0.001$ & $4 \cdot 1$ & $5(62 \cdot 5)$ & $3(37 \cdot 5)$ \\
\hline Cervical spine disorder & 20 & 6 & $<0.001$ & $3 \cdot 1$ & $2(33)$ & $4(67)$ \\
\hline Postherpetic trigeminal neuralgia & 1 & 6 & $<0.001$ & $3 \cdot 1$ & $4(67)$ & $2(33)$ \\
\hline Post-traumatic & 88 & 4 & NS & $2 \cdot 1$ & $4(100)$ & $0(0)$ \\
\hline \multicolumn{7}{|l|}{ Eyes, ears, nose, sinuses, teeth, jaws } \\
\hline disorder & 32 & 4 & NS & $2 \cdot 1$ & $1(25)$ & $3(75)$ \\
\hline Cluster & 71 & 3 & NS & 1.5 & $3(100)$ & $0(0)$ \\
\hline Benign cough & 3 & 3 & $<0.001$ & 1.5 & $3(100)$ & $0(0)$ \\
\hline Accelerated hypertension & 2 & 3 & $<0.001$ & 1.5 & $1(33)$ & $2(67)$ \\
\hline Intracranial haematoma & 0 & 2 & $<0.001$ & $1 \cdot 0$ & $1(50)$ & $1(50)$ \\
\hline Substance misuse or withdrawal & 40 & 2 & NS & $1 \cdot 0$ & $1(50)$ & $1(50)$ \\
\hline Occipital neuralgia & 11 & 2 & NS & $1 \cdot 0$ & $1(50)$ & $1(50)$ \\
\hline Migraine & 1801 & 1 & $<0.001$ & 0.5 & $1(100)$ & $0(0)$ \\
\hline Tolosa-Hunt syndrome & 2 & i & NS & 0.5 & $0(0)$ & $1(100)$ \\
\hline Facial pain not classifiable & 13 & 2 & NS & $1 \cdot 0$ & $0(0)$ & $2(100)$ \\
\hline Other diagnosis $\ddagger$ & 147 & 0 & $<0.02$ & & & \\
\hline Totals & 3385 & 193 & & $5 \cdot 4$ & 7137 & 12263 \\
\hline
\end{tabular}

${ }^{\star} \chi^{2}$ test.

† Sex distribution of patients aged 65 and over.

$\ddagger$ Miscellaneous headaches unassociated with structural lesions, headaches associated with vascular disorders, with non-vascular intracranial disorder, with non-cephalic infection, and with metabolic disorders and cranial neuralgias.

$63 \%)$ than in men $(71$ cases, $37 \%)$. No statistically significant differences were found between the group of patients in whom headache started when under 65 and the group in whom headache began when aged 65 and over.

Post-traumatic, cluster, and benign cough headaches were the only headaches almost exclusive to men. Tension type headache ( 83 patients, $43 \%$ of all the aged patients) and idiopathic trigeminal neuralgia (36 patients, $19 \%$ ) were the most frequent diagnoses; then isolated headache as the first and main symptom of subarachnoid haemorrhage (15 patients, $8 \%$ ), temporal arteritis (12 patients, $6 \%$ ), and headache as the first symptom of intracranial tumours-three skull base tumours and five brain hemispheric tumours (eight patients, 4\%). Finally, six patients were diagnosed as having headache secondary to cervical spine disorder, six postherpetic trigeminal neuralgia, four post-traumatic headache, four headache associated with disorders of the nose, sinuses, teeth, and jaws (one glaucoma, one dental infection, and two acute sinus infections), three cluster headache, and three benign cough headache. The remaining 11 patients met the criteria for other diagnoses including accelerated hypertension, intracranial haematoma, headache secondary to medications, occipital neuralgia, migraine without aura, Tolosa-Hunt syndrome, and facial pain not fulfilling criteria for cranial neuralgias.

Tension type headache, migraine, and other diagnosis began significantly more often in patients under 65 , whereas trigeminal neuralgia, headache secondary to vascular disorders (subarachnoid haemorrhage, temporal arteritis, accelerated hypertension, and intracranial haematoma), headache secondary to cervical disorder, and benign cough headache were significantly more common in patients after 65 . The proportion of the remaining diagnoses was not statistically different for the two age groups (table).

\section{Discussion}

Because many, even elderly, patients with headaches either never go to a doctor, or are exclusively treated by their general practitioner, the data presented here do not have any direct epidemiological value. They should, however, be of practical interest to neurologists working in developed countries.

Historically, it has been thought that the incidence of headache in elderly people is inversely related to age, and that headache may more often herald serious conditions such as stroke, temporal arteritis, or intracranial neoplasm in the aged population. ${ }^{5}$ The data of the present study are in agreement with both assumptions. Headaches beginning after 65 represented only $5.4 \%$ of all the headaches in this series, whereas $12 \cdot 1 \%$ of the population in the area of our hospital is 65 or older. Even without taking into account migraine, which reached $50.4 \%$ of headaches in the total population, headaches beginning in elderly people represented $11 \%$ of consultations-that is, still lower than the percentage of subjects over 65 in the general population.

On the other hand, at least in our general hospital, it is true that headache is secondary to serious conditions, such as stroke, temporal arteritis, or intracranial neoplasms more often in elderly people than in those under 65 . In this series $15 \%$ of elderly patients presenting with headache had one of these serious disorders, whereas only $1.6 \%$ of those presenting with headache under 65 had such a serious disorder.

The most frequent diagnosis in the aged was tension type headache, which accounted for nearly half of all head pains beginning after 65 . Because tension type headache may be associated with depression, sleep disorders, and situational life changes, ${ }^{2-4}$ it seems logical to find this headache often in elderly people. Nevertheless, this high incidence of tension type headache is only relative; in fact, consultations because of de novo tension type 
headache were more common in subjects under 65. In our experience tension type headache beginning after 65 justified only $7.5 \%$ of overall consultations due to this diagnosis, clearly below $12 \cdot 1 \%$, the percentage of old people in our community. This concurs with the study of Langemark and coworkers, ${ }^{11}$ in which only a small percentage (under $5 \%$ ) of patients with tension type headache report their age at onset of headache as over 60 .

Apart from tension type headache, headache secondary to substance misuse or withdrawal and, above all, migraine began more commonly before 65 . Whereas the prevalence of migraine over 65 is high $(7 \%$ in men and $12 \%$ in women), ${ }^{2}$ its onset is unusual after $60(2 \%){ }^{12}$ Although migraine accounted for $50 \%$ of the total series, only one patient out of 1802 met the current criteria for migraine diagnosis after 65 , which represents only $0.5 \%$ of headaches in this series.

By contrast with migraine, entities such as headache secondary to vascular disorders, headache secondary to intracranial neoplasm, both postherpetic and idiopathic trigeminal neuralgia, and benign cough headache were almost exclusive to or predominant in those patients starting with headaches over 65 . On the other hand, consultations due to headache secondary to eyes, ears, nose, sinuses, teeth, and jaw disorder, facial pain not classifiable, cluster headache, and occipital neuralgia were statistically similar in patients older and younger than 65 .

We are indebted to John Hawkins and Jesús Pascual for their stylistic revision of the manuscript.

1 Rasmussen BK, Olesen J. Symptomatic and nonsymptomatic headaches in a general population. Neurology 1992;42:1225-31.

2 Cook N, Evans DA, Funkenstein $\mathrm{H}$, et al. Correlates of headache in a population-based cohort of elderly. Arch Neurol 1989;46:1338-44.

3 Serratrice G, Serbanesco F, Sambuc R. Epidemiology of headache in elderly-Correlations with life conditions and socio-professional environment. Headache 1985;25: 85-9.

4 Hale WE, May FE, Marks RG, Moore MT, Steward RB. Headache in the elderly: an evaluation of risks factors. Headache 1987;27:272-6.

5 Waters WE. Community studies of the prevalence of headache. Headache 1970;9:178-86.

6 Waters WE. The Pontypridd headache survey. Headache 1974;14:81-90.

7 Ziegler DK, Hassanein RS, Couch JR. Characteristics of life headache histories in a nonclinic population. Neurology 1977; 27:265-9.

8 Levy LM. An epidemiological study of headache in an urban population in Zimbabwe. Headache 1982;23:2-9.

9 Baumel B, Eisner LS. Diagnosis and treatment of headache in the elderly. In: Diamond S, ed. The medical clinics of North America. Headache. Philadelphia: WB Saunders, 1991;75:661-75.

10 Headache Classification Committee of the International Headache Society. Classification and diagnostic criteria for headache disorders, cranial neuralgias and facial pain. Cephalalgia 1988;8:(suppl 7):1-96.

11 Langemark M, Olsen J, Poulsen DL, et al. Clinical characterization of patients with chronic tension headaches. terization of patients with

12 Stang PE, Yanagihara T, Swanson JW, et al. Incidence of migraine headache: A population-based study in Olmsted County, Minnesota. Neurology 1992;42. $1657-62$ 